\title{
Enhancing ESL Learners' Sentence Construction via Sentence-Combining Practice
}

\author{
Tengku Ahmad Kamal bin Tengku Abdul Rahman ${ }^{1,2}$, Nur Ehsan bin Mohd Said ${ }^{2}$ \\ 1. Sekolah Kebangsaan Merang, Setiu, Terengganu \\ 2. Faculty of Education, Universiti Kebangsaan Malaysia \\ DOI: 10.29322/IJSRP.11.06.2021.p11451 \\ http://dx.doi.org/10.29322/IJSRP.11.06.2021.p11451
}

\begin{abstract}
The capacity to write well helps learners do well in exams because writing has always been a significant type of evaluation in colleges and greater education establishments. However, only a portion of learners, primarily with greater skills, can perform well in English. Whilst many learners from Malaysia drop into the lesser bracket, particularly rural students. The objective of this study was to examine whether sentence-combining practice, a written intervention, was effective in improving written expression in English for comparison and contrast for year six students who have been fighting literacy. This research utilized a quasi-experimental with pre-test post-test design. The researcher collected a convenience sample of learners in the literacy class at a rural primary school in Setiu, Terengganu. All of the learners improved their ability to combine sentences, improved the quality of their stories, and the unit length per sentence did increase for all of the learners.
\end{abstract}

Index Terms- ESL learners, sentence-combining, sentence construction.

\section{INTRODUCTION}

Writing training in English as a second language and pedagogy have experienced a multi-faceted evolution in the methods and methodologies used in various teaching settings. Approaches such as product and method design guidelines, metacognition, thoughtaloud protocols, a gender-based strategy, content-based approaches and many more are used and examined within certain teaching purposes and results. Nevertheless, the many methods accessible are still regarded difficult for many teachers because of the multiple difficulties encountered by the classes and the multiple demands, skills and aspirations of students.

Malaysian learners, particularly rural students, experience English writing difficulties. The Malaysian Ministry of Education has announced that the first challenge is to obtain the data required to address the query, so that the learners are unable to remember what they have heard about the issue. The second is the failure to create exciting and reflective thoughts, which leads to monotonous works. The third deficiency is that thoughts are not obviously and consistently displayed, leading to misunderstanding about the concepts submitted. The fourth is that paragraphs or essays cannot be planned in a coherent manner that often results in repeat and meaningless thoughts and an absence of direction in their content. The absence of exposure to English has always been an obstacle for learners in rural environments. Students in rural classrooms are not able to type well in English. Writing in English is a fight for them because in English they have no decent basis. How do teachers deal with students who cannot even make right phrases in English, or often students who do not even try to start writing because they do not speak the language? Many of them are secondary and cannot write yet. This implies their future and their path to tertiary education that requires English for educational reasons.

The objective of this study was to examine whether sentence combining practice, a written intervention, was effective in improving knowledge acquisition and written expression in English for comparison and contrast for year six students who have been fighting literacy. The study not only has developed literacy skills in English, but also enhances linguistic knowledge of English content similarities and contrasts by means of written intervention in English. In order to satisfy disciplinary literacy requirements, a study basis for empirical research is needed in order to report and validate efficient written procedures in these fields (Mo, Kopke, Hawkins, Troia and Olinghouse, 2014). For students who fight for literacy, but have the same training as all students, education is even more essential (Saddler \& Asaro-Saddler, 2013). Researchers have documented the effectiveness of a sentence that combines written accomplishment for students who combat literacy (Graham \& Perin, 2007). However, study into phrases and scholarly writings is lacking.

\section{A. ESL Learners' Writing Difficulties}

\section{LITERATURE REVIEW}

Chou (2011) has mentioned several explanations why ESL students experience many stresses and barriers in writing their jobs. Firstly, learners from a variety of cultural backgrounds may be totally dependent on educators. They were also not taught to be critical thinkers and could have reduced standards than their educators because they regard themselves as second language learners. Writing educators 
with elevated aspirations could assume that students are sufficiently skilled to create correct texts and could also attach challenging subjects that students might struggle with when they write (Al Murshidi, 2014). Low language skills could also hinder academic writing. Ghabool, Edwina and Kashef (2012) say the fundamental cause of problems that learners have in writing could be this issue. For example, it is very difficult for the novice writers to discuss effectively in the target language (Shafie et al, 2010). As Al-Khairy (2013) found, his research participants stated that their significant issues include grammatical errors, improper selection of vocabulary, uneven verbal and improper punctuation and orthography.

\section{B. The Process of Writing Instruction}

Although the written work is obviously valuable and complex, Troia and Maddox (2004) notice that specialist and general educators surveyed learned writing abilities without sufficient assistance or a complete curriculum for writing. The traditional reading lessons consisted of imitating excellent designs, frequent exercise and teacher-led editions used to refine the written item made by learners. Instructional changes with their roots in the early 1970s resulted to process-oriented written measures from these product-orientated methods. Instead of concentrating on the end item, teachers started shifting their lessons to affect what they were composing. For instance, teachers are supported in brainstorming methods for composing thoughts and adapting their job to get a stronger feel for their crowd. The change in this strategy resulted not only in educational modifications, but also in modifications in the era of introduction to reading in schools, as teaching was traditionally emphasized in middle and high schools (Berninger \& Winn, 2006). A process-oriented action strategy calls for the creation of teachable approaches that emphasize a more effective use of the three main written procedures: scheduling, sentencing and reviews.

\section{Sentence-Combining}

Sentence-Combining (SC) is a research-based procedure aimed at learning within a metalinguistic structure by facilitating the metalinguistic procedures required to consciously build written phrases (Scott \& Nelson, 2009). SC is also an action relying on grammar. SC manipulates and rewrites kernels or brief declarative phrases in fresh syntactically complicated types. This speech enhances authors ' understanding of phrase constructions and ideas through regular and repetitive forming and reformation of sentences (Saddler \& Graham 2005). In fact, a writer investigates alternative combinations of phrase structures which may or may not have the same significance or purpose during SC.

The exercise of SC can then be used as a plan to enhance, edit or revise the reading of learners (Saddler \& Preschern, 2007). SC was commended as the best option to traditional grammar (Andrews et al., 2006). SC has a big study base (Scott, 2009) which has made SC the most frequently suggested syntax and writing interventions (Eberhardt, 2013). SC was reported to enhance simplified (a) phrase building (Scott, 2009), (b) syntactic strength (O'Hare, 1973), and (c) submitted performance (Saddler, Asaro, \& Behforooz, 2008). Researchers have also considered SC a legitimate procedure for the written assessment, development and documentation of development (Nelson, 2013).

SC has previously been criticized for its absence of formal or deliberate assessment of syntactic structure and its inductive exercise of creating grammar judgements. Although SC used the exercise of grammar in context, it did not involve the capacity to describe or then describe inacceptable components of the phrases with grammatical phrases. These allegations and the misunderstandings were prevalent with SC because of the absence of comprehension of how SC operations are to be conducted. Strong suggested a metalinguistic approach to $\mathrm{SC}$, with the aim of building awareness of the connection between spoken and written language by reading phrases and thinking aloud and thus shaping one's prose into the same intent.

The unclear findings recorded throughout SC's literature have stopped the hypothesis of SC's written guidance from being solidified. In the last two centuries, there have been little study on SC training written and read; however, present study is arising. Scott (2009) has argued that speaking and writing about sentencing complexity can assist learners to acknowledge and deconstruct complicated structures vital to understanding reading. When studying text, the abstractness and difficulty of students struggling with these abilities is considerably increased by the reader in the subsequent primary and secondary college (Scott \& Koonce, 2014). Students with reading problems often have syntactic problems whether they are diagnosed with or not (Scott \& Koonce, 2014).

\section{METHODOLOGY}

This research utilized a quasi-experimental with pre-test post-test design. Ninety-four sixth grade students from the primary school in Setiu, Terengganu, made up the subjects in this study. Forty-seven students comprised the control group, and forty-seven students were given to sentence combining treatment in the experimental group. The control group and the experimental group both consisted of two classes of sixth grade students. The control group and the experimental group were not equated in ability in that one of the control classes had significantly higher I.Q. scores, and had been labelled "gifted and talented." The other control class was heterogeneously mixed. Students in both experimental groups were heterogeneously mixed. The subjects came from a generally rural community of Setiu District in Terengganu. 


\section{A. Reading Comprehension}

\section{RESULTS}

Table 1(a) Comparison of Reading Comprehension Pre-test and Post-test Score

\begin{tabular}{lcccccc}
\hline & \multicolumn{3}{c}{ Control } & \multicolumn{3}{c}{ Experimental } \\
\cline { 2 - 7 } & Class 1 & Class 2 & Mean & Class 1 & Class 2 & Mean \\
\hline Pre-test Mean & 54.69 & 34.00 & 44.35 & 34.56 & 32.75 & 33.65 \\
Post-test Mean & 57.03 & 42.29 & 49.66 & 44.26 & 41.20 & 42.73 \\
Raw Growth Score & 2.34 & 8.29 & 5.32 & 9.70 & 8.45 & 9.12 \\
Grade Equivalent Score & 0.47 & 1.72 & 1.10 & 1.90 & 1.64 & 1.77 \\
\hline
\end{tabular}

Table 1(b) Comparison of the Reading Comprehension Score of the Experimental Groups and Control Class 2

\begin{tabular}{lcc}
\hline & Control Class 2 & Experimental Class 1 \& 2 \\
\hline Pre-test Mean & 34.00 & 33.65 \\
Post-test Mean & 42.29 & 43.75 \\
Raw Score Growth & 8.29 & 10.08 \\
Grade Equivalent Growth & 1.72 & 1.77 \\
\hline
\end{tabular}

Table 1(a) shows that the growth rate for the experimental group and the second control class was more than four times as great as the growth rate for the "gifted and talented" class. It should be noted in Table l(b) that the gains made by the experimental group were only slightly greater than the gains made by control class 2 . Thus, the experimental group and control class 2 show a nearly equal growth rate.

\section{B. Writing}

Table 2(a) Comparison of Writing as Assessed by T-Units between Experimental and Control Groups

\begin{tabular}{lcccccc}
\hline & \multicolumn{3}{c}{ Control Group } & \multicolumn{3}{c}{ Experimental Group } \\
\cline { 2 - 7 } & Class 1 & Class 2 & Mean & Class 1 & Class 2 & Mean \\
\hline Words Per T-Unit & 10.34 & 8.56 & 9.45 & 9.93 & 9.84 & 9.88 \\
\hline
\end{tabular}

Table 2(b) Analysis of Variance

\begin{tabular}{|c|c|c|c|c|}
\hline Source & SS & df & MS & $\mathbf{F}$ \\
\hline Treatment & 0.33 & 1 & 0.03 & 0.01 \\
\hline Error & 352.94 & 92 & 3.84 & \\
\hline Total & 352.97 & 93 & & \\
\hline
\end{tabular}

Crit $\mathrm{F}=5.22$ at 0.05

Table 2(c) Analysis of Covariance

\begin{tabular}{|c|c|c|c|c|}
\hline Source & SS & df & MS & $\mathbf{F}$ \\
\hline Treatment & 0.98 & 1 & 0.98 & 0.28 \\
\hline Error & 323.59 & 91 & 3.56 & \\
\hline Total & 324.57 & 92 & & \\
\hline
\end{tabular}

Table 2(d) Post-Hoc Analysis Comparison of T-Units between Experimental Class $1 \& 2$ and Control Class 2

\begin{tabular}{lcc}
\hline & Control Class 2 & Experimental Class 1 \& 2 \\
\hline Words per Unit & 8.56 & 9.88 \\
Standard Deviation & 1.44 & 1.53 \\
\hline
\end{tabular}

Critical $\mathrm{t}=2.015, \mathrm{t}=9.69$

Significant at the 0.05 
Table 2(a) shows a comparison of the mean scores of the T-unit assessment between the experimental and control classes. The mean for the experimental classes was slightly higher than the mean for the control classes, and at the .05 level of confidence, the results showed no significant difference between the two groups. The formula for the Analysis of Covariance was applied to the results, but the difference between the results of the two formulas was negligible and not significant at the .05 level. The differences in the Critical $\mathrm{F}$ between the results of the Analysis of Variance and the Analysis of Covariance can be seen in Tables 2(b) and 2(c). Since the control class 2 and the experimental group were equated in ability, the scores of these classes were applied to a t-test to determine whether or not the difference in the scores was significant. Table 2(d) presents this comparison as a Post-hoc Analysis. The results favoured the experimental group and were significant at the .05 level.

\section{DISCUSSION}

This experiment sought to determine the effectiveness of sentence combining on the reading and writing of sixth grade students. The results of the study can be looked at from several different ways. When comparing the experimental group with both control classes, it was shown that the classes which received sentence-combining practice were better able to identify specific transformations in sentences. When comparing the experimental group with control class 1, which was the "gifted and talented" class, there was no significant difference in their ability to identify parts of speech. In fact, the "gifted and talented" class actually had the higher mean score. This performance was to be expected since this class was a higher ability group of students to begin with, and they had received instruction in parts of speech. The fact that there were not significantly higher than the experimental classes is noteworthy. When comparing the experimental group with control class 2, the difference in scores was significant, favouring the experimental classes. Therefore, on the basis of these results, it would appear that sentence combining practices can be an effective approach to teach English. When comparing the reading comprehension between the experimental group and the control group, the results were significant in favour of the control group. Again, this performance was to be expected since the "gifted and talented" class was already established as a group of higherlevel ability students. However, when the experimental classes were compared only with the control class 2 , the results were nearly equal. Thus, it cannot be said by the results from the experiment that practice in sentence combining will enhance reading comprehension growth.

The comparison of the experimental group and the control group on the writing samples showed no significant difference, even though the data was put through the formula for the analysis of covariance. The purpose of this formula is to adjust for differences in ability. The difference in the adjustment, however, was negligible. The scores for the experimental classes and the "gifted and talented" were very nearly equal with the "gifted and talented" class slightly edging the experimental group. However, when the t-test for significance was administered to compare the scores of the experimental group and the control class 2, the scores for the experimental group were found to be significantly higher.

\section{CONCLUSION}

Thus, it can be said from these findings that sentence combining can be used as an effective strategy to enhance writing skills for comparison and contrast for year six students who have been fighting literacy. The results of this experiment determine that sentence combining is an effective tool in improving written expression in English. The results did not indicate in any way that sentence combining practices affect the students' reading comprehension. Perhaps this could be discovered using a different design with less emphasis on transformations and grammatical terminology.

\section{REFERENCES}

Al-Khairy, Mohamed. (2013). Saudi English-Major Undergraduates' Academic Writing Problems: A Taif University Perspective. English Language Teaching. 6. 10.5539/elt.v6n6p1.

Al Murshidi, Ghadah. (2014). Emirati and Saudi Students' Writing Challenges at U.S. Universities. English Language Teaching. 7. $10.5539 /$ elt.v7n6p87.

Andrews, R., Torgerson, C., Beverton, S., Freeman, A., Locke, T., Low, G., Robinson, A., \& Zhu, D. (2006). The effect of grammar teaching on writing development. British Educational Research Journal, 32, 39-55. Retrieved from http://www.jstor.org/stable/30032657

Berninger, V. W., Abbott, R. D., Abbott, S. P., Graham, S., \& Richards, T. (2002). Writing and reading: Connections between language by hand and language by eye. Journal of Learning Disabilities, 35, 39-56. doi:10.1177/002221940203500104

Berninger, V. W., \& Winn, W. D. (2006). Implications of advancements in brain research and technology for writing development, writing instruction, an educational evolution. In C. A. MacArthur, S. Graham, \& J. Fitzgerald (Eds.), Handbook of writing research (pp. 96- 114). New York: The Guilford Press.

Chou, P.T.-M. (2011). The effects of vocabulary knowledge and background knowledge on reading comprehension of Taiwanese EFL students. Electronic Journal of Foreign Language Teaching. 8. 108-115.

Eberhardt, N. C. (2013). Syntax: Somewhere between words and text. Perspectives on Language and Literacy, 39(3), 43-49.

Ghabool, N., Edwina, M., \& Kashef, H. S. (2012). Investigating Malaysian ESL students 'writing problems on conventions, punctuation, and language use at secondary level. Journal of Studies in Education, 2(3), 131-143.

Graham, S. (2006). Writing. In P. Alexander \& P. Winne (Eds.), Handbook of educational psychology (pp. 457-477). Mahwah, NJ: Lawrence Erlbaum.

Graham, S., \& Harris, K. R. (1993). Self-regulated strategy development: Helping students with learning problems develop as writers. Elementary School Journal, 94, 169-181. doi:10.1086/461758

Graham, S., \& Harris, K. R. (1999). Assessment and intervention in overcoming writing difficulties: An illustration from the self-regulated strategy development model. Language, Speech, and Hearing Services in Schools, 30, 255-264. Retrieved from http://lshss.asha.org/cgi/content/abstract/30/3/255

Graham, S., \& Harris, K. R. (2003). Students with learning disabilities and the process of writing: A meta-analysis of SRSD studies. In H. L. Swanson, K. R. Harris, \& S. Graham (Eds.), Handbook of learning disabilities (pp. 323-344). New York: Guilford.

This publication is licensed under Creative Commons Attribution CC BY.

http://dx.doi.org/10.29322/IJSRP.11.06.2021.p11451

www.ijsrp.org 


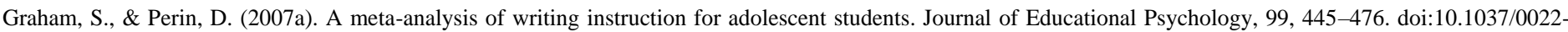
0663.99 .3 .445

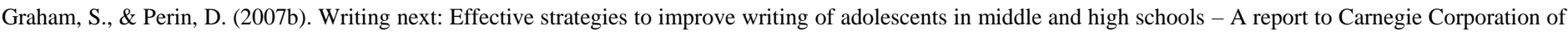
New York. Washington, DC: Alliance for Excellent Education.

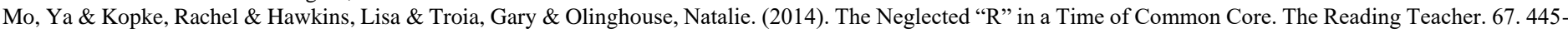
453. 10.1002/trtr.1227.

Nelson, R. (2013). Practice as research in the arts: Principles, protocols, pedagogies, resistances. Springer.

O'Hare, F. (1973). Sentence Combining: Improving Student Writing without Formal Grammar Instruction. NCTE Committee on Research Report Series. No. 15.

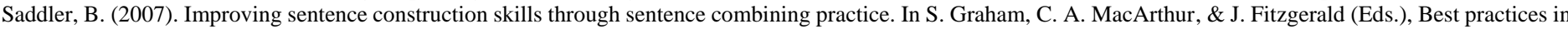
writing instruction (pp. 163-178). New York: Guilford.

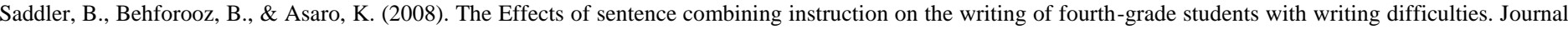
of Special Education, 42, 79-90. doi:10.1177/0022466907310371

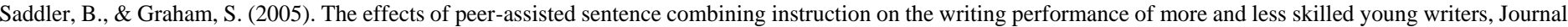
of Educational Psychology, 97, 43-54. doi:10.1037/0022-0663.97.1.43

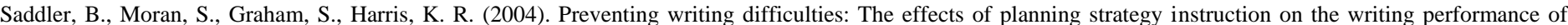
struggling writers. Exceptionality, 12, 3-17. doi:10.1207/s15327035ex1201_2

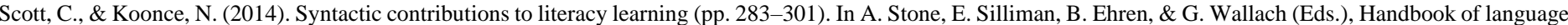
and literacy: Development and disorders (2nd ed.). New York, NY: Guilford

Scott, C. M. (2009). A case for the sentence in reading comprehension. Language, speech, and hearing services in schools.

Scott C. M., Nelson NW. Sentence combining: Assessment and intervention applications. Perspectives on Language Learning and Education. 2009;16:14-20.

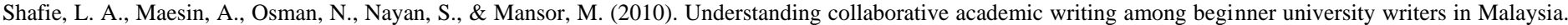
Studies in Literature and Language, 1, 58-69.

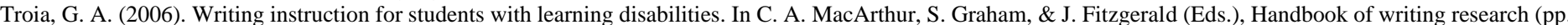
324-336). New York: The Guilford Press.

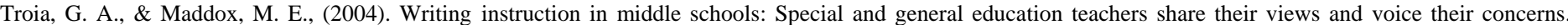
Exceptionality, 12, 19-37. doi:10.1207/s15327035ex1201_3

\section{AUTHORS}

First Author - Tengku Ahmad Kamal bin Tengku Abdul Rahman, B.Sc. (Hons), Dip.Ed., Sekolah Kebangsaan Merang, Setiu, Terengganu, Malaysia. tengkukamal273@gmail.com.

Correspondence Author - Nur Ehsan bin Mohd Said, Centre of Innovation in Teaching \& Learning, Faculty of Education, Universiti Kebangsaan Malaysia. nurehsan@ukm.edu.my. 